\title{
PESQUISA DE ENTEROBACTERIÁCEAS E ENTEROVIRUS EM CRIANÇAS NORMAIS E COM QUADROS DIARRÉICOS AGUDOS (1)
}

\author{
José Alberto N. CANDEIAS (2) \\ Sebastião Timo IARIA (2) \\ Dacio de Almeida CHRISTOVÃO (2) \\ Ary Walter SCHMID (2) \\ Augusto de Escragnolle TAUNAY (3) \\ Luiz G. COTILLO Z. (2)
}

\begin{abstract}
Num grupo de 263 criancas de 0 a 24 meses de idade, atendidas de outubro de 1963 a setembro de 1964 no Centro de Saúde da Lapa, na Capital de São Paulo, foram feitos exames de fezes para a pesquisa de Escherichia coli, do grupo da gastroenterite infantil, Shigella, Salmonella, poliovirus, vírus Coxsackie e vírus ECHO. O agente mais freqüentemente isolado foi o vírus da poliomielite (15,97\% de positividade), seguindo-se-lhe a Escherichia coli G.E.I. (10,65\%), Shigella $(9,51 \%)$, vírus Coxsackie $(7,22 \%)$, Salmonella em $3,04 \%$ dos casos e vírus ECHO no mesmo percentual. Em 16,22\% das 111 que apresentaram resultado positivo, o exame revelou a presença de dois ou mais agentes. Os agentes acima referidos foram isolados de $42,21 \%$ da totalidade das criancas examinadas. Dentre as $16 \%$ que apresentavam diarréia, a percentagem de positividade chegou a $47,90 \%$, e nas 96 que năo a referiam, desceu a $32,29 \%$. Sòmente em relação às shigelas foi possivel evidenciar associação entre isolamento de microrganismos e quadro diarréico. Para a E. coli o111, salmonelas e virus Coxsackie $A$, os resultados foram apenas sugestivos desta associaçáo, e para os demais agentes não houve evidência alguma favorável à mesma.
\end{abstract}

\section{N T R O D U C A O}

A freqüência com que, na literatura médica, se encontram trabalhos abordando o problema das diarréias, é uma sugestiva indicação de sua importância para o clínico, o microbiologista e o sanitarista. Não obstante, a maioria das investigações limita-se ao isolamento de determinado agente etiológico ou a provas sorológicas, em casos clínicos, parecendo não levar em consideração o quanto se torna indispensável o estudo comparado com grupos contrôles normais (TAUNAY et alii ${ }^{30}, 1956$; Talnay et alii ${ }^{31}$, 1958; Ramos-AlvareZ \& Sabin ${ }^{24}$, 1958; Sommerville ${ }^{23}, 1958$;

Recebido para publicação em 2-10-1968.

(1) Da Cadeira de Microbiologia Aplicada da Faculdade de Higiene e Saúde Pública da USP. Trabalho realizado com o auxilio da Bôlsa MED 2-62 concedida pela Fundação de Amparo à Pesquisa do Estado de São Paulo.

(2) Da Cadeira de Microbiologia Aplicada da FHSP.

(3) Chefe da Secção de Bacteriologia do Instituto Adolfo Lutz da Secretaria da Saúde do Estado de São Paulo. 
CANDEIAS, J. A. N. et alil - Pesquisa de enterobacteriáceas e enterovirus em criancas normais e com quadros diarréicos agudos. Rev. Saúde públ., São Paulo, 2(2):194-206, dez. 1968.

Costa, Costa \& Bolaños $\left.{ }^{3}, 1959\right)$ e o quanto é importante a procura de associações de agentes, como bactérias, vírus, protozoáriós e helmintos (Maroja, Freitas \& Ferro ${ }^{14}$, 1959; Young et alii ${ }^{39}, 1962$ ). E desnecessário considerar os erros de interpretação a que tal tipo de orientação pode levar.

Em nosso meio, os trabalhos sôbre o isolamento de enterobacteriáceas e sua responsabilidade por quadro diarréico são numerosos e levam a resultados afirmativamente concludentes (PeLufFo ${ }^{21}$, 1946; Maroja \& Lowerey ${ }^{15}$, 1956; Costa, Costa \& Brooking ${ }^{4}$, 1957; Moraes ${ }^{17}$, 1960; RouQuayrol ${ }^{26}$, 1962; MurahovsCHI et alii ${ }^{18}, 1963$; FERRARI $\left.{ }^{5}, 1964\right)$ ). Já a participação dos enterovírus nêstes quadros clínicos não só não tem sido tão estudada, mas também os resultados não são de molde a confirmar semelhante relação (Travassos et alii ${ }^{32}, 1952 / 1953$; Lobo ${ }^{13}$, 1962; Schatzmayr \& Sales ${ }^{27}$; 1966; Carvalho ${ }^{2}$, 1966). Num como noutro caso, os estudos não abrangem duas amostras comparáveis, com e sem diarréia.

A finalidade do presente trabalho foi estudar dois grupos de crianças, com e sem diarréia, tanto quanto possível comparáveis, a fim de verificar as percenta- gens de isolamento de enterobacteriáceas e enterovírus, contribuindo, de certo modo, para o esclarecimento da etiologia das doenças diarréicas, além de fornecer dados sôbre a prevalência dos agentes isolados, nos referidos grupos.

\section{MATERIAL E ME.TODOS}

Amostragem - Um total de 263 crianças, de 0 a 24 meses de idade, atendidas no Centro de Saúde da Lapa - São Paulo, foi utilizado nêste trabalho. Nesta amostra circunstancial, 167 crianças apresentavam diarréia e 96 mostravam-se normais. Foram consideradas crianças com diarréia aquelas com número de evacuações diárias aumentado e cujas fezes se apresentavam com consistência líquida. Crianças normais eram as que não apresentavam nem diarréia, nem quadros com sintomatologia respiratória. A percentagem de $63,50 \%$ de crianças com diarréia sôbre o total examinado é, sensivelmente, respeitada em cada um dos grupos etários, em que foi dividida a amostra, o mesmo ocorrendo com a percentagem de $36,50 \%$ que representa o grupo de crianças sem diarréia, em relação ao total. Esta distribuição torna a amostra homogênea quanto a êste fator (Tabela 1).

TA B E L A 1

Distribuição das crianças examinadas, segundo a idade e a presença ou ausência de diarréia

\begin{tabular}{|c|c|c|c|c|c|}
\hline \multirow{3}{*}{$\begin{array}{l}\text { Idade } \\
\text { em } \\
\text { meses }\end{array}$} & \multirow{3}{*}{$\begin{array}{l}\text { Número de } \\
\text { crianças } \\
\text { examinadas }\end{array}$} & \multicolumn{4}{|c|}{ Diarréia } \\
\hline & & \multicolumn{2}{|c|}{ Presente } & \multicolumn{2}{|c|}{ Ausente } \\
\hline & & No & $\%$ & No & $\%$ \\
\hline $01-6$ & 87 & 54 & 62,07 & 33 & 37,93 \\
\hline $61-12$ & 81 & 51 & 62,96 & 30 & 37,04 \\
\hline $12 \mid-18$ & 50 & 32 & 64,00 & 18 & 36,00 \\
\hline $181-24$ & 45 & 30 & 66,67 & 15 & 33,33 \\
\hline Total & 263 & 167 & 63,50 & 96 & 36,50 \\
\hline
\end{tabular}


CANDEIAS, J. A. N. et alii - Pesquisa de enterobacteriáceas e enterovírus em crianças normais r com quadros diarrélcos agudos. Rev. Saúde públ., São Paulo, 2(2):194-206, dez. 1968.

Mais de $30 \%$ das crianças examinadas pertencia ao grupo etário de 0 a 6 meses, ao passo que nas demais idades a percentagem baixava progressivamente, chegando a $17 \%$ no grupo de 18 a 24 meses de idade. Em cada grupo etário as percentagens mensais variaram amplamente, devido ao número relativamente pequeno de crianças examinadas (Tabela 2).

Colheida do material - A colheita de fezes foi feita nos meses de outubro a dezembro de 1963 e de janeiro a setembro de 1964. Seguiu-se a técnica do "swab" retal. 0 material destinado ao exame bacteriológico era colocado em glicerina tamponada, o mesmo sucedendo com as cânulas de borracha utilizadas para a introdução retal dos "swabs". O "swab" destinado à pesquisa virológica era, prèviamente, umedecido com solução salina de Hanks contendo 200 unidades de penicilina sódica e $0,1 \mathrm{mg}$ de estrep- tomicina por ml. Após a colheita, êste "swab" era mergulhado em solução salina de Hanks contendo 2.000 unidades de penicilina sódica e $2 \mathrm{mg}$ de estreptomicina por $\mathrm{ml}$ e congelado a $-20^{\circ} \mathrm{C}$ até início do exame.

Métodos bacteriológicos - Após serem homogeneizadas, por agitação, as amostras emulsionadas em glicerina tamponada eram passadas diretamente em placas de agar SS, de meio de H.H. Teague e de agar verde brilhante. Semeava-se também $1 \mathrm{ml}$ de cada emulsão em caldo selenito e caldo tetrationato adicionado de verde brilhante, do qual, após 24 horas de incubação a $37^{\circ} \mathrm{C}$, se faziam passagens em novas placas de agar SS e meio de Teague e agar verde brilhante. De tôdas as placas, após incubação a $37^{\circ} \mathrm{C}$ por 24 horas realizava-se o isolamento de colônias, cuja identificação era feita posteriormente por meio de provas bioquímicas e sorológicas. No caso da $E$. coli G.E.I.,

T A B E L A 2

Distribuição mensal das crianças examinadas, segundo a idade

\begin{tabular}{|c|c|c|c|c|c|c|c|c|c|}
\hline \multirow{3}{*}{ Mês } & \multirow{3}{*}{$\begin{array}{l}\text { Número } \\
\text { de } \\
\text { criancas } \\
\text { exami- } \\
\text { nadas }\end{array}$} & \multicolumn{8}{|c|}{ Idade em meses } \\
\hline & & \multicolumn{2}{|c|}{$01-6$} & \multicolumn{2}{|c|}{$61-12$} & \multicolumn{2}{|c|}{$121-18$} & \multicolumn{2}{|c|}{$18\lceil-24$} \\
\hline & & No & $\%$ & No & $\%$ & $\mathrm{~N}^{\circ}$ & $\%$ & Ne & $\%$ \\
\hline Outubro 1963 & 22 & 4 & 18,18 & 8 & 36,36 & 3 & 13,64 & 7 & 31,82 \\
\hline Novembro & 34 & 8 & 23,53 & 11 & 32,35 & 7 & 20,59 & 8 & 23,53 \\
\hline Dezembro & 24 & 6 & 25,00 & 7 & 29,17 & 7 & 29,17 & 4 & 16,67 \\
\hline Janeiro 1964 & 40 & 14 & 35,00 & 11 & 27,50 & 11 & 27,50 & 4 & 10,00 \\
\hline Fevereiro & 29 & 14 & 48,28 & $\mathbf{5}$ & 17,24 & 1 & 3,45 & 9 & $\mathbf{3 1 , 0 3}$ \\
\hline Março & 48 & 17 & 35,42 & 15 & 31,25 & 8 & 16,67 & 8 & 16,67 \\
\hline Abril & 一 & - & - & - & - & 一 & - & - & - \\
\hline Maio & 20 & 2 & 10,00 & 11 & 55,00 & 6 & 30,00 & 1 & 5,00 \\
\hline Junho & 16 & 9 & 56,25 & 5 & 31,25 & 2 & 12,50 & - & - \\
\hline Julho & - & - & - & 一 & 一 & - & - & - & - \\
\hline Agôsto & 20 & 9 & 45,00 & 4 & 20,00 & 3 & 15,00 & 4 & 20,00 \\
\hline Setembro & 10 & 4 & 40,00 & 4 & 40,00 & 2 & 20,00 & - & - \\
\hline Total & 263 & 87 & 33,08 & 81 & 30,80 & 50 & 19,01 & 45 & 17,11 \\
\hline
\end{tabular}


CANDEIAS, J. A. N. et alis - Pesquisa de enterobacterláceas e enterovirus em crianças normais e com quadros diarréicos agudos. Rev. Saúde públ., São Paulo, 2(2):194-206, dez. 1968.

sud identificação sorológica foi feita por provas de aglutinação em lâmina e em tubos, com os soros específicos.

Métodos virológicos - Depois de descongeladas, as amostras de fezes eram inoculadas em culturas de células HeLa, âmnio humano e rim de macaco Rhesus, num volume de inóculo de $0,2 \mathrm{ml}$ por amostra.

As células $\mathrm{HeLa}$ eram mantidas em meio de Hanks com 5\% de hidrolisado de lactalbumina, sem sôro. As células primárias de âmnio humano eram mantidas em Earle com 51\% de lactalbumina, vitaminas e aminoácidos e $5 \%$ de sôro de cavalo, inativado. As células de rim de macaco Rhesus eram mantidas em meio 199. Todos os meios eram adicionados de penicilina e estreptomicina numa concentração de 200 unidades e 0,1 $\mathrm{mg}$ por $\mathrm{ml}$.

As amostras eram inoculadas em 4 tubos de cultura, de cada tipo de células, incubadas a $37^{\circ} \mathrm{C}$ e observadas cada dois dias, para verificação da presença de efeito citopático. Eram consideradas negativas as amostras que não apresentavam efeito citopático em duas passagens de 21 dias cada. Cada amostra era ainda inoculada, por via subcutânea, em camundongos recém-nascidos de idade compreendida entre 24 e 48 horas, na dose de $0,02 \mathrm{ml}$ por animal, usando-se 5 animais por amostra. Estes eram mantidos em observação durante 14 dias, sacrificando-se um animal cada 7 dias, para passagens sucessivas. Uma amostra era considerada negativa sòmente depois de duas passagens sem sintomas característicos de infecção. A identificação das amostras isoladas era feita de acôrdo com a técnica descrita por Gamble et alii ${ }^{\circledR}$ (1963).

A identificação das amostras de poliovírus e vírus ECHO era feita por provas de neutralização com "pools" de soros (Hambling, Davies \& Macrae ${ }^{10}, 1963$ ).
RESULTADOS

A Tabela 3 mostra a distribuição mensal dos exames positivos para bactérias e vírus, com uma percentagem de positividade total de $42,21 \%$. No grupo com diarréia esta percentagem eleva-se para $47,90 \%$, descendo a $32,29 \%$ no grupo sem diarréia. Supondo que as duas amostras sejam semelhantes em todos os atributos relevantes exceto quanto à diarréia, a aplicação da prova de significância bicaudal revela que a diferença encontrada, $15,61 \%$, é significante ao nível de $5 \%$. Os dados mensais são insuficientes para que se faça uma análise mais precisa da distribuição cronológica dos resultados positivos.

$\mathrm{Na}$ Tabela 4 discriminamos as associações de agentes observados. Nas fezes de uma criança isolaram-se duas espécies bacterianas; em 16 crianças uma bactéria e um vírus; sòmente numa criança foi iso. lada uma bactéria associada com dois vírus diferentes. Assim, em 18 crianças, ou seja, em 16,22\% das 111 que apresentaram resultados positivos, o exame revelou a presença de dois ou mais agentes. Este total de 18 crianças em que se isolou mais de um agente distribui-se, nos dois grupos estudados, do seguinte modo: 15 casos no grupo com diarréia e 3 casos no grupo sem diarréia.

Encontra-se na Tabela 5 a distribuição dos resultados conforme a presença ou ausência de diarréia e as bactérias e vírus isolados. Foram isoladas bactérias das fezes de $23,19 \%$ das crianças, proporção pouco inferior à encontrada para os vírus, que atingiu $26,24 \%$. 0 agente mais freqüentemente isolado foi o vírus da poliomielite, em 15,97\% dos casos, seguindo-se-lhe a Escherichia coli G.E.I. em $10,65 \%$, Shigella, 9,51\%, vírus Coxsackie, $7,22 \%$ e finalmente Salmonella e vírus ECHO, encontrados em $3,04 \%$ das crianças.

Em relação às bactérias, o percentual de crianças com diarréia que apresentaram resultado positivo, $31,14 \%$, é muito 
CANDEIAS, J. A. N. et alii - Pesquisa de enterobacteriaceas e enterovirus em crianças normais e com quadros diarréicos agudos. Rev. Saúde públ., São Paulo, 2(2):194-206, dez. 1968.

TA B E L A 3

Distribuição mensal das crianças examinadas, segundo a presença ou ausência de diarréia e o isolamento de bacterias ou virus

\begin{tabular}{|c|c|c|c|c|c|c|c|c|c|}
\hline \multirow{4}{*}{ Mês } & \multirow{4}{*}{$\begin{array}{c}\text { Número } \\
\text { de } \\
\text { criancas } \\
\text { examinadas }\end{array}$} & \multirow{3}{*}{\multicolumn{2}{|c|}{$\begin{array}{c}\text { Exames } \\
\text { positivos }\end{array}$}} & \multicolumn{6}{|c|}{ D i ar ré la } \\
\hline & & & & \multicolumn{3}{|c|}{ Presente } & \multicolumn{3}{|c|}{ Ausente } \\
\hline & & & & \multirow{2}{*}{$\begin{array}{l}\text { Número } \\
\text { de } \\
\text { exames }\end{array}$} & \multicolumn{2}{|c|}{$\begin{array}{l}\text { Exames } \\
\text { positivos }\end{array}$} & \multirow{2}{*}{$\begin{array}{c}\text { Número } \\
\text { de } \\
\text { exames }\end{array}$} & \multicolumn{2}{|c|}{$\begin{array}{l}\text { Exames } \\
\text { positivos }\end{array}$} \\
\hline & & No & $\%$ & & Ne & $\%$ & & No & $\%$ \\
\hline Outubro 1963 & 22 & 11 & 50,00 & 22 & 11 & 50,00 & $\mathbf{0}$ & 一 & 一 \\
\hline Novembro & 34 & 20 & 58,82 & 34 & 20 & 58,82 & 0 & 一 & - \\
\hline Dezembro & 24 & 11 & 45,83 & 24 & 11 & 45,83 & 0 & 一 & 一 \\
\hline Janeiro 1964 & 40 & 19 & 47,50 & 19 & 9 & 47,37 & 21 & 10 & 47,62 \\
\hline Fevereiro & 29 & 15 & 51,72 & 12 & 8 & 66,67 & 17 & 7 & 41,18 \\
\hline Março & 48 & 14 & 29,17 & 22 & 7 & $\mathbf{3 1 , 8 2}$ & 26 & 7 & 26,92 \\
\hline Abril & - & 一 & 一 & - & - & - & - & 一 & - \\
\hline Maio & 20 & 7 & 35.00 & 10 & 5 & 50,00 & 10 & 2 & 20,00 \\
\hline Junho & 16 & 4 & 25,00 & 9 & 4 & 44,44 & 7 & 0 & - \\
\hline Julho & - & - & - & - & - & - & - & - & - \\
\hline Agôsto & 20 & 9 & 45,00 & 10 & 4 & 40,00 & 10 & 5 & 50,00 \\
\hline Setembro & 10 & 1 & 10,00 & $\mathbf{5}$ & 1 & 20,00 & $\mathbf{5}$ & $\mathbf{0}$ & - \\
\hline Total & 263 & 111 & 42,21 & 167 & 80 & 47,90 & 96 & 31 & 32,29 \\
\hline
\end{tabular}

T A B E L A 4

Distribuição das crianças examinadas, segundo a presenca ou ausêncla de diarréia e as associações de bactérias e virus

\begin{tabular}{|c|c|c|c|c|c|c|c|}
\hline & \multirow{3}{*}{ Agentes Isolados } & \multirow{2}{*}{\multicolumn{2}{|c|}{$\begin{array}{c}\text { Criancas } \\
\text { examinadas } \\
(263)\end{array}$}} & \multicolumn{4}{|c|}{ Diarréia } \\
\hline & & & & \multicolumn{2}{|c|}{$\begin{array}{c}\text { Presente } \\
\text { (167) }\end{array}$} & \multicolumn{2}{|c|}{$\begin{array}{c}\text { Ausente } \\
\text { (96) }\end{array}$} \\
\hline & & No & $\%$ & Ne & $\%$ & No & $\%$ \\
\hline Bactérias & $\begin{array}{l}\text { E. coli G.E.I. } \\
\text { Shigella } \\
\text { Salmonella } \\
\text { E. coli G.E.I. + Shigella }\end{array}$ & $\begin{array}{r}20 \\
16 \\
6 \\
1\end{array}$ & $\begin{array}{l}7,60 \\
6,08 \\
2,28 \\
0,38\end{array}$ & $\begin{array}{r}15 \\
15 \\
6 \\
1\end{array}$ & $\begin{array}{l}8,98 \\
8,98 \\
3,59 \\
0,60\end{array}$ & $\begin{array}{l}5 \\
1 \\
0 \\
0\end{array}$ & $\begin{array}{l}5,21 \\
1,04 \\
- \\
-\end{array}$ \\
\hline Virus & $\begin{array}{l}\text { Polio } \\
\text { Coxsackle } \\
\text { ECHO }\end{array}$ & $\begin{array}{r}32 \\
13 \\
6\end{array}$ & $\begin{array}{r}12,17 \\
4,94 \\
2,28\end{array}$ & $\begin{array}{r}17 \\
9 \\
3\end{array}$ & $\begin{array}{r}10,18 \\
5,39 \\
1,80\end{array}$ & $\begin{array}{r}15 \\
4 \\
3\end{array}$ & $\begin{array}{r}15,63 \\
4,17 \\
3,13\end{array}$ \\
\hline $\begin{array}{l}\text { Bactérias } \\
\quad+ \\
\text { Virus }\end{array}$ & $\begin{array}{l}\text { E. coli G.E.I. + Polio } \\
\text { E. coli G.E.I. + Coxsackle } \\
\text { E. coli G.E.I. + ECHO } \\
\text { E. coli G.E.I. + Polio + Coxsackie } \\
\text { Shigella + Polio } \\
\text { Shigella + Coxsackie } \\
\text { Shigella + ECHO } \\
\text { Salmonella + Polio } \\
\text { Salmonella + Coxsackle }\end{array}$ & $\begin{array}{l}2 \\
3 \\
1 \\
1 \\
6 \\
1 \\
1 \\
1 \\
1\end{array}$ & $\begin{array}{l}0,76 \\
1,14 \\
0,38 \\
0,38 \\
2,28 \\
0,38 \\
0,38 \\
0,38 \\
0,38\end{array}$ & $\begin{array}{l}0 \\
2 \\
1 \\
1 \\
6 \\
1 \\
1 \\
1 \\
1\end{array}$ & $\begin{array}{l}\overline{1,20} \\
0,60 \\
0,60 \\
3,59 \\
0,60 \\
0,60 \\
0,60 \\
0,60\end{array}$ & $\begin{array}{l}2 \\
1 \\
0 \\
0 \\
0 \\
0 \\
0 \\
0 \\
0\end{array}$ & $\begin{array}{l}2,08 \\
1,04 \\
= \\
= \\
= \\
-\end{array}$ \\
\hline Total & & 111 & 42,21 & 80 & 47,90 & 31 & 32,29 \\
\hline
\end{tabular}


CANDEIAS, J. A. N. et alil - Pesquisa de enterobacteriáceas e enterovirus em crlanças normais e com quadros diarréicos agudos. Rev. Saúde públ., São Paulo, 2(2):194-206, dez. 1968.

superior ao observado no caso das crianças sem diarréia, que alcançou $9,38 \%$; a diferença revelou-se significante ao nivel de $5 \%$. Para os vírus, o grupo com diarréia apresentou um percentual de positividade de $26,35 \%$, pràticamente igual ao grupo sem diarréia, com uma percentagem de $26,04 \%$. A comparação entre a percentagem de positividade para cada um dos agentes nas crianças com e nas sem diarréia revela uma diferença significante ao nível de $5 \%$ apenas no caso da Shigella.

Observe-se que o total de 130 resultados positivos difere do encontrado na Tabela 4 (111 crianças com resultados positivos), devido ao fato de que 17 crianças apresentavam dois microrganismos diferentes nas fezes e uma apresentava três, - que, em têrmos de resultados corresponderá a 34 e 3 , respectivamente; se a êstes valores juntarmos os 93 resultados com isolamento de um só gérmen, teremos o referido valor de 130 .

Encontra-se na Tabela 6 a relação dos exames positivos para bactérias após a respectiva tipagem sorológica. Convém notar que neste caso o total de exames positivos é 62 , e não 61 , como na Tabela 4, pois em uma criança isolou-se $E$. coli 055 e também $E$. coli 0125 . Foram isolados 9 tipos diferentes de $E$. coli G.E.I., não parecendo haver diferença entre as percentagens de isolamento nas crianças com e sem diarréia. Quanto às shigelas e salmonelas, foram isolados respectivamente 6 e 3 tipos diferentes. E pertinente observar que apenas uma shigela ( $S$. flexneri II) foi encontrada em criança sem diarréia, ao passo que neste mesmo grupo de crianças nenhuma albergava salmonelas.

Apresentamos na Tabela 7 os resultados da tipagem dos vírus. Quanto aos poliovírus, foi isolado com maior freqüência o tipo I, vindo a seguir o III e por fim o tipo II. As crianças com e as sem diarréia comportaram-se de modo aproximadamente igual quanto ao encontro dêstes vírus. Foram isolados virus Coxsackie A (tipos Al, Al2 e A13) de 6 crianças, tôdas com diarréia; isolaram-se também vírus Coxsackie B (tipos B2 a B5) de 12 casos, dos quais 7 apresentavam diarréia

T A B E L A 5

Distrlbulção dos resultados, segundo a presença ou ausência de diarréia e as bactérias e os vírus isolados

\begin{tabular}{|c|c|c|c|c|c|c|c|}
\hline & \multirow{3}{*}{ Agentes Isolados } & \multirow{2}{*}{\multicolumn{2}{|c|}{$\begin{array}{c}\text { Criancas } \\
\text { examinadas } \\
(263)\end{array}$}} & \multicolumn{4}{|c|}{ Diarréia } \\
\hline & & & & \multicolumn{2}{|c|}{$\begin{array}{c}\text { Presente } \\
\text { (167) }\end{array}$} & \multicolumn{2}{|c|}{$\begin{array}{c}\text { Ausente } \\
\text { (96) }\end{array}$} \\
\hline & & No & $\%$ & Ne & $\%$ & $N^{\circ}$ & $\%$ \\
\hline \multirow[t]{2}{*}{ Bactérias } & $\begin{array}{l}\text { E. coli G.E.I. } \\
\text { Shigella } \\
\text { Salmonella }\end{array}$ & $\begin{array}{r}28 \\
25 \\
8\end{array}$ & $\begin{array}{r}10,65 \\
9,51 \\
3,04 \\
\end{array}$ & $\begin{array}{r}20 \\
24 \\
8\end{array}$ & $\begin{array}{r}11,98 \\
14,37 \\
4,79 \\
\end{array}$ & $\begin{array}{l}8 \\
1 \\
0\end{array}$ & $\begin{array}{l}8,33 \\
1,04 \\
- \\
\end{array}$ \\
\hline & Sub-total & 61 & 23,19 & $\mathbf{5 2}$ & 31,14 & 9 & $\mathbf{9 , 3 8}$ \\
\hline \multirow[t]{2}{*}{ Virus } & $\begin{array}{l}\text { Polio } \\
\text { Coxsackle } \\
\text { ECHO } \\
\end{array}$ & $\begin{array}{r}42 \\
19 \\
8\end{array}$ & $\begin{array}{r}15,97 \\
7,22 \\
3,04 \\
\end{array}$ & $\begin{array}{r}25 \\
14 \\
5\end{array}$ & $\begin{array}{r}14,97 \\
8,38 \\
2,99\end{array}$ & $\begin{array}{r}17 \\
5 \\
3 \\
\end{array}$ & $\begin{array}{r}17,71 \\
\mathbf{5 , 2 1} \\
\mathbf{3 , 1 3} \\
\end{array}$ \\
\hline & Sub-total & 69 & 26,24 & 44 & 26,35 & 25 & 26,04 \\
\hline Total & & 130 & 49,43 & 96 & 57,49 & 34 & 35,42 \\
\hline
\end{tabular}


CANDEIAS, J. A. N. et alii - Pesquisa de enterobacteriáceas e enterovirus em criancas normais e com quadros diarréicos agudos. Rev. Saúde públ., São Paulo, z(2):194-206, dez. 1968.

TA B E L A 6

Distribuição dos resultados positivos para bactérias, segundo as respectivas espécies ou tipos e a presença ou auséncia de diarréia

\begin{tabular}{|c|c|c|c|c|}
\hline \multirow{2}{*}{\multicolumn{2}{|c|}{ Agentes Isolados }} & \multirow{2}{*}{$\begin{array}{l}\text { Exames } \\
\text { Positivos }\end{array}$} & \multicolumn{2}{|c|}{ Diarréia } \\
\hline & & & Presente & Ausente \\
\hline E. coli G.E.T & $\begin{array}{l}026 \\
055 \\
086 \\
0111 \\
0112 \\
0119 \\
0125 \\
0126 \\
0128\end{array}$ & $\begin{array}{l}1 \\
4 \\
3 \\
7 \\
1 \\
1 \\
6 \\
2 \\
4\end{array}$ & $\begin{array}{l}1 \\
3 \\
2 \\
6 \\
0 \\
1 \\
3 * \\
1 \\
3\end{array}$ & $\begin{array}{l}0 \\
1 * * \\
1 \\
1 \\
1 \\
0 \\
3 * * \\
1 \\
1\end{array}$ \\
\hline 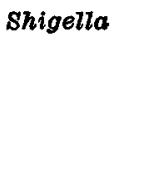 & 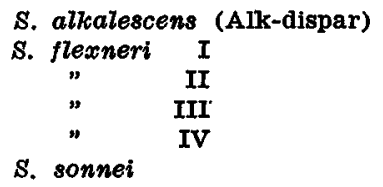 & $\begin{array}{l}1 \\
\mathbf{3} \\
\mathbf{5} \\
\mathbf{8} \\
\mathbf{1} \\
\mathbf{7}\end{array}$ & $\begin{array}{l}1 \\
3 \\
4 \\
8 * \\
1 \\
7\end{array}$ & $\begin{array}{l}0 \\
0 \\
1 \\
0 \\
0 \\
0\end{array}$ \\
\hline Salmonella & $\begin{array}{l}\text { S. derby } \\
\text { S. newport } \\
\text { S. panama }\end{array}$ & $\begin{array}{l}6 \\
1 \\
1\end{array}$ & $\begin{array}{l}6 \\
1 \\
1\end{array}$ & $\begin{array}{l}0 \\
0 \\
0\end{array}$ \\
\hline Total & & 62 & 52 & 10 \\
\hline
\end{tabular}

- De uma crianca isolou-se S. flexneri III e $E$. coli 0125.

* De uma crianca isolou-se $E$, coli 055 e $E$, coli 0125 .

T A B E L A 7

Distribuição dos resultados positivos para vírus, segundo os respectivos tipos e a presença ou ausência de diarréia

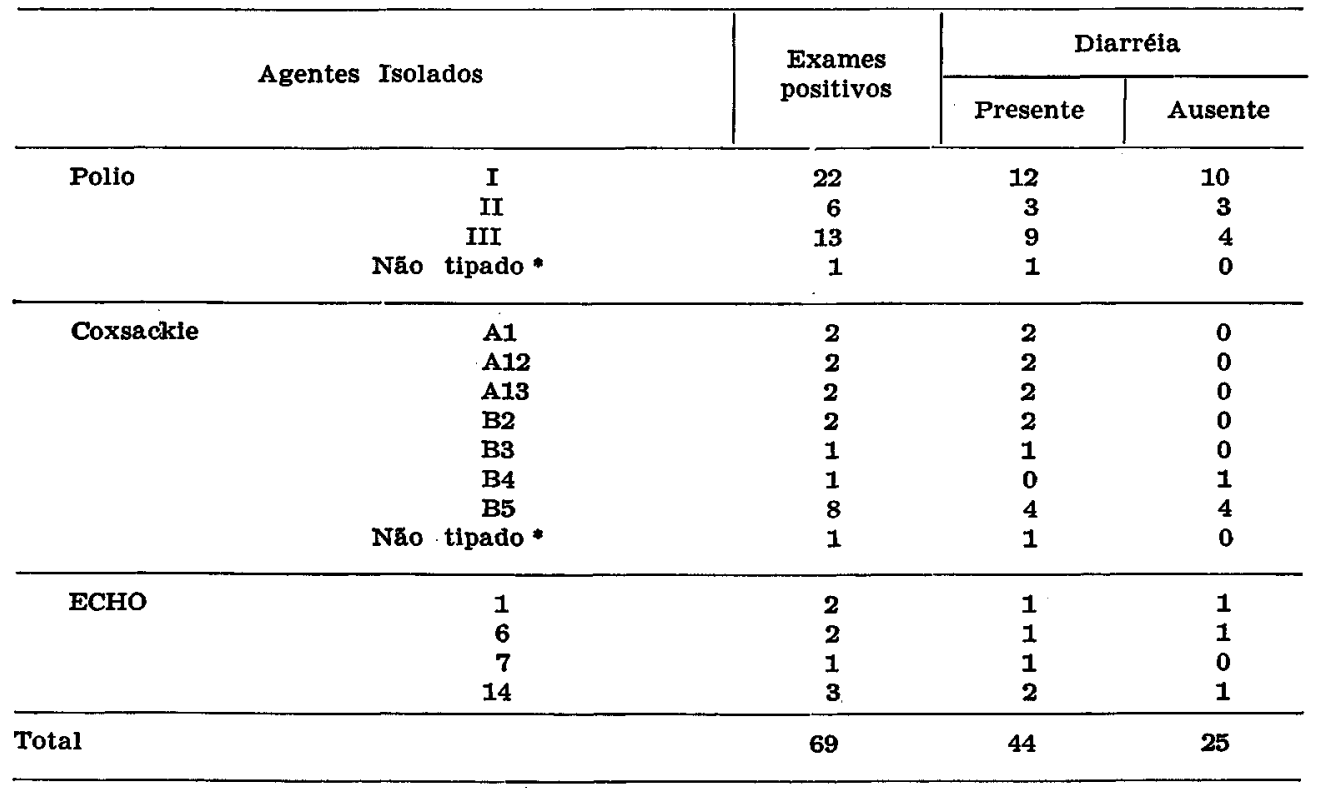

* Ambos foram isolados de uma só crlanca. 


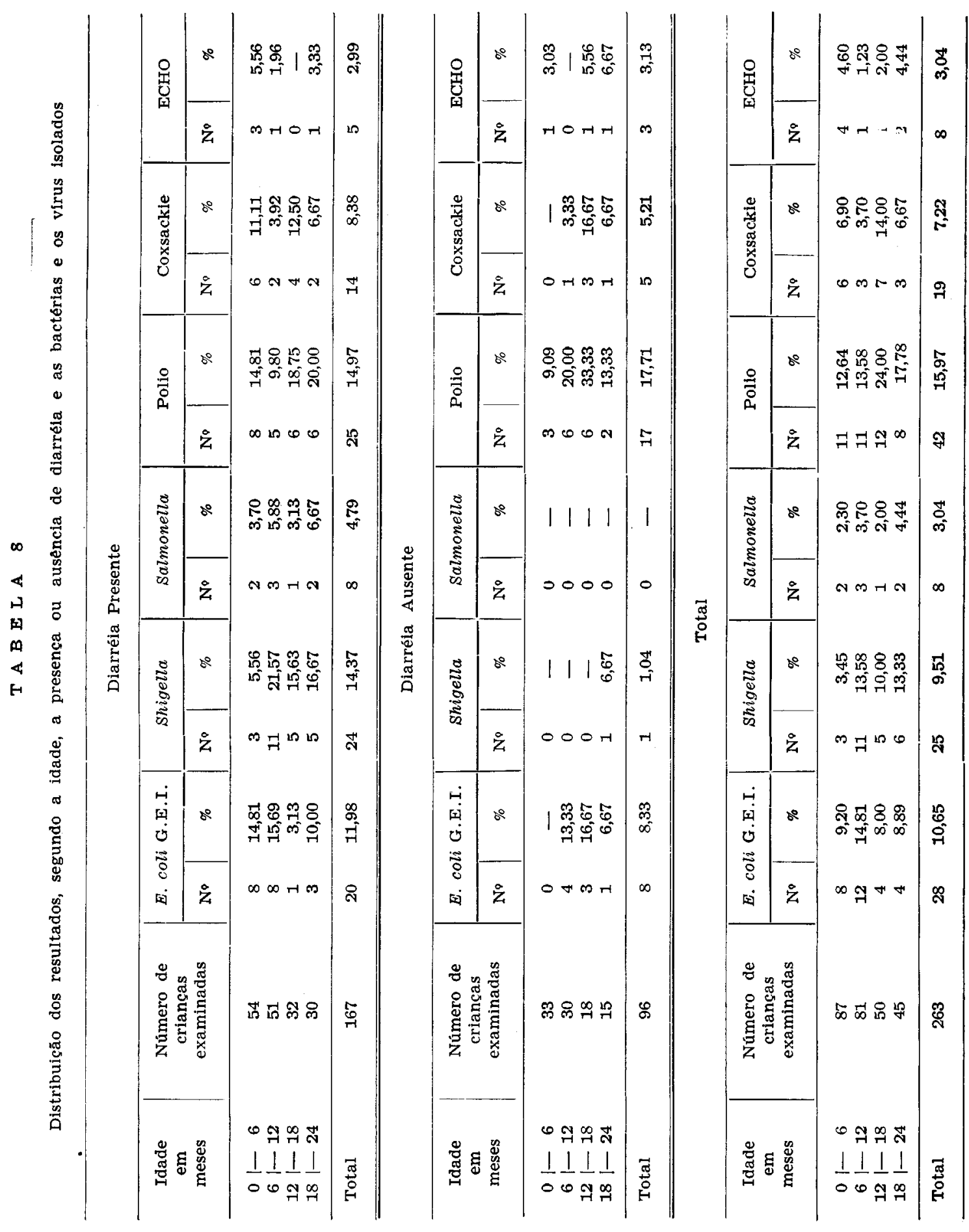


CANDEIAs, J. A. N. et alii - Pesquisa de enterobacteriáceas e enterovirus em crianças normais e com quadros diarréicos agudos. Rev. Saúde públ., São Paulo, 2(2):194-206, dez. 1968.

e 5 não a referiam. Uma criança albergava poliovírus e Coxsackie, que não foram tipados. Os vírus ECHO (tipos 1, $6,7,14$ ) foram encontrados em 8 crianças: 5 com e 3 sem diarréia.

A Tabela 8 discrimina os resultados obtidos segundo a idade, a presença ou ausência de diarréia e os agentes isolados. A análise das variações que se observam nos percentuais de positividade para cada agente, ao se confrontarem os grupos etários entre si, não sugere qualquer tendência, ascendente ou descendente. Os únicos resultados que consideramos passíveis de serem ressaltados são, em primeiro lugar, a total ausência de isolamentos de E. coli G.E.I. no grupo etário de 0 a 6 meses, nas crianças sem diarréia, contra $14,81 \%$ no grupo de crianças com diarréia; em segundo lugar, é flagrante a total ausência de isolamentos de salmonelas nas crianças sem diarréia para todos os grupos etários; situação semelhante ocorre em relação às shigelas, excetuando o grupo de 18 a 24 meses.

\section{I S C U S S A O}

$O$ primeiro fato que deve ser ressaltado é a elevada percentagem de crianças com resultados positivos, tanto no grupo que apresentava diarréia, com $47,90 \%$, como naquele que não a referia, com $32,29 \%$ (Tabela 3). As bactérias e os vírus que estamos estudando transmitemse preponderantemente através das fezes: o alto percentual de exames positivos que encontramos, em ambos os grupos, mostra que êstes microrganismos estão amplamente disseminados no ambiente em que vivem estas crianças. A diferença significante que encontramos entre os dois grupos sugere, òbviamente, que alguns dêstes agentes podem ser os responsáveis pela diarréia. $O$ encontro de alta percentagem de positividade nas crianças sem diarréia indica que êstes microrganismos podem causar infecção sem o aparecimento dệste sintoma.
Os enterovírus foram isolados em proporção pouco superior à das bactérias, ou seja, $26,24 \%$ e $23,19 \%$ respectivamente. Encarando globalmente o grupo dos três vírus estudados, verifica-se que o percentual de isolamento é pràticamente igual nas crianças com e nas sem diarréia. Logo, nossos dados sugerem que êstes vírus não devem ser causa importante na gênese desta síndrome. Já a diferença encontrada entre os dois mesmos grupos, quanto ao isolamento de bactérias, é significativa, podendo-se levantar a hipótese de que a diarréia deva ocorrer sobretudo devido à presença das shigelas.

Cumpre destacar que as enterobacteriáceas e os enterovírus têm sido isolados com grande freqüência, mesmo nas coletividades em que é bom o saneamento do meio. Ramos-Alvarez ${ }^{22}$ (1957) isolou, das fezes de 56 crianças com diarrẻia, em Cincinnati, EUA, 3 poliovírus, 7 vírus ECHO, 7 Coxsackie, um adenovírus e 6 vírus não classificados. Ramos-Alvarez \& SABIN ${ }^{23}$ (1954) referem o encontro de 5 poliovírus, um Coxsackie e 25 outros vírus causadores de efeito citopático em 1.566 crianças sadias de Cincinnati e Xenia, o que representa uma positividade de $2 \%$. Os mesmos autores (Ramos-AlvaREZ \& S SABIN $\left.{ }^{25}, 1956\right)$, compararam êstes resultados com os encontrados nas cidades de Veracruz e do México, em que do material de 1.771 crianças sadias foram isoladas 334 cêpas de vírus, o que equivale à positividade de $19 \%$. Ramos-Alvarez \& SABIN ${ }^{24}$ (1958) relatam os resultados encontrados em dois grupos de crianças de Cincinnati: o vírus ECHO foi encontrado em $31 \%$ de 97 crianças com diarréia, e apenas em $5 \%$ de 100 crianças que não a apresentavam; o poliovírus foi isolado em $3 \%$ das crianças, em cada um dos grupos, e o Coxsackie em $4 \%$ das com diarréia e em $6 \%$ das crianças sadias. Neste mesmo trabalho, de 86 crianças com diarréia isolou-se em $30 \%$ dos casos E. coli G.E.I. e em 7\% Shigella ou Salmonella. De 64 crianças sem diarréia foi isolada $E$. coli G.E.I. em $20 \%$ 
CANDEIAS, J. A. N. et alii - Pesquisa de enterobacteriáceas e enterovírus em crianças normais e com quadros diarrélcos agudos. Rev. Saúde públ., São Paulo, 2(2):194-206, dez. 1968.

das vêzes. Sommerville ${ }^{28}$ (1958), em dois grupos de crianças da Escócia, encontrou $21 \%$ de positividade para vírus nas com diarréia e $14 \%$ em outro grupo, com afecções respiratórias. No entanto, a comparação entre êstes dois grupos, para cada um dos três enterovírus, isoladamente, não mostrou haver associação entre a sua presença e a diarréia.

Em nosso grupo de crianças, o encontro de dois ou mais microrganismos no material de uma mesma criança foi muito comum, pois ocorreu em 18 oportunidades, ou seja, em 16,22\% das 111 que apresentavam resultado positivo (Tabela 5). A associação mais freqüente foi Shigella e poliovírus, em 6 casos; por outro lado, - microrganismo mais vêzes encontrado associado a outros foi o poliovírus, em 10 crianças, vindo em seguida a Shigella e a $E$. coli G.E.I., respectivamente em 9 e 8 crianças.

Sommerville ${ }^{28}$ (1958), no estudo já referido, encontrou uma bactéria patogênica e um vírus na mesma amostra de fezes em $6,8 \%$ das crianças com diarréia. Younc et alli ${ }^{33}$ (1962), em 29 crianças com gastroenterite, residentes em San Juan, Pôrto Rico, pesquisando bactérias, vírus, protozoários e helmintos, encontrou $41 \%$ albergando mais de um agente em suas fezes.

Êstes fatos vêm reforçar as nossas considerações iniciais, no sentido de que é conveniente proceder à pesquisa simultânea de bactérias, vírus e outros agentes no mesmo grupo de pessoas para que se possa afirmar com certa segurança que um determinado microrganismo é o responsável pelo quadro clínico.

No caso da $E$. coli G.E.I., nossos dados não evidenciaram diferença significativa entre o percentual de positividade nas crianças com e nas sem diarrëia (Tabela 4). Contudo, para a $E$. coli 0111 encontramos 6 individuos com diarréia albergando êste agente contra apenas um no outro grupo, o que confirma, mais uma vez, uma associação entre o encontro da bactéria e a presença dêste quadro clínico
(Tabela 6). Já outros autores observaram idêntica relação, não só para o tipo 0111 , mas também para outros tipos ( $\mathrm{T}_{\mathrm{AU}}$ NAY et alii ${ }^{30,31}$, 1956, 1958; MAROJA et alii ${ }^{16}$, 1958; Maroja, Freitas \& FerRO ${ }^{14}$, 1959; Fischer ${ }^{6}$, 1961; MURAhovsCHI et alii ${ }^{18}, 1963$ ).

No material que utilizamos, foram isoladas shigelas de $14,37 \%$ das crianças com diarréia e apenas de $1,04 \%$ no outro grupo (Tabela 4), diferença que é significante estatisticamente. Encontramos $S$. flexneri em 17 crianças e $S$. sonnei em 7; em um caso foi isolada a $S$. alkalescens, que é hoje colocada por muitos no grupo Escrerichia (grupo Alkalescens-dispar).

No caso das salmonelas encontramos resultados positivos em apenas 8 crianças, tôdas com diarréia $(S$. derby em $6, S$. newport è uma e $S$. panama também em uma criança). Este resultado sugere a responsabilidade destas bactérias como agentes etiológicos, apesar da prova de significância não ter revelado associação entre a sua presença e a ocorrência de diarréia, o que provàvelmente, se deve à técnica de colheita usando o "swab" retal (TAunaY ${ }^{29}, 1967$ ). Aliás, sabe-se que as salmonelas de origem animal produzem infecções em que predomina a gastroenterite, se bem que seu isolamento seja menos freqüente do que de shigelas $e$ E. coli G.E.I. (Hormaeche et alii ${ }^{11}$, 1943; Costa, Costa \& Brooking ${ }^{4}$, 1957; TaUnaY et alii ${ }^{31}, 1958$; Maroja et alii ${ }^{16}$, 1958; Maroja, Freitas \& Ferro ${ }^{14}$, 1959; RouquaYrol ${ }^{26}, 1962$ ). Existem, no entanto, casos em que as salmonelas são mais freqüentemente isoladas, como é a situação descrita por FourNelle, Gracián \& Medina ${ }^{7}$ (1966), na Colômbia: das fezes de 1.846 pessoas com diarréia atual ou recente, isolaram 132 salmonelas, 84 shigelas, 21 Alkalescens-dispar e 20 cêpas de $E$. coli G.E.I.

Os vírus da poliomielite foram os agen. tes mais comumente isolados do material das crianças estudadas, com um percentual de positividade de $15,97 \%$, embora 
CANDEIAS, J. A. N. et alii - Pesquisa de enterobacteriáceas e enterovirus em crianças normais e com quadros diarréicos agudos. Rev. Saúde públ., São Paulo, 2(2):194-206, dez. 1968.

nenhuma apresentasse quadro clínico sugestivo da moléstia. Os dois grupos que estamos comparando apresentaram proporções de isolamento semelhantes: na realidade, as crianças com diarréia tiveram um percentual de positividade de 14,97\%, inferior ao observado nas sem diarréia, com um valor de 17,71\%. Em 67 crianças que apresentavam doenças que não a poliomielite paralítica, Carvalho ${ }^{2}$ (1966) encontrou $12 \%$ com poliovírus, proporção semelhante à que obtivemos. Em trabalho a ser publicado, Candeias \& ChrisTOVÃo ${ }^{1}$, utilizando a serodiferenciação intratípica, encontraram elevada percentagem de cêpas de vacina Sabin ou com características semelhantes entre as amostras de poliovírus isoladas no presente trabalho.

Quanto aos vírus Coxsackie, foram isolados das fezes de $7,22 \%$ das crianças examinadas, $8,38 \%$ no grupo com diarréia e $5,21 \%$ no grupo não diarréico, diferença que não é significante. No entanto, o Coxsackie A só foi encontrado em crianças com diarréia (Tabela 7), o que confirma os achados de vários autores de que o grupo A pode estar associado a quadros diarréicos (PARrott ${ }^{20}$, 1957). Os vírus Coxsackie $B$ foram igualmente isolados em ambos os grupos.

GAMBLE $^{3}$ (1962) encontrou numa amostra casual de 2.084 crianças, em Londres, 6,6\% albergando vírus Coxsackie, sendo 112 isolamentos do grupo A e 26 do grupo B. Travassos et alii ${ }^{32}$ (1952/1953), no Rio de Janeiro, nas fezes de 20 lactentes com distúrbios gastrointestinais, referem o isolamento de Coxsackie em 9 oportunidades, o que representa a elevada proporção de $45 \%$.

$\mathrm{O}$ escasso número de crianças de cujas fezes isolamos vírus ECHO impede que se faça uma análise mais profunda dos dados. Ramos-Alvarez \& SabiN ${ }^{24}$ (1958), como vimos, isolaram êste vírus de crianças com diarréia em uma proporção 6 vêzes maior que em outro grupo, de crianças sadias. Êste vírus se encontra amplamente disseminado nas Filipinas, como afirma OCAMPo ${ }^{19}$ (1967), tendo sido assinalada a sua presença em muitos surtos epidêmicos de diarréia ocorridos em várias comunidades, como se depreende da revisão do assunto feita por KIBRICK ${ }^{12}$ (1964).

Os dados da Tabela 8, em que apresentamos a distribuição das crianças examinadas segundo a idade, a presença de diarréia e os agentes isolados, permitem que se façam dois comentários principais: todos os microrganismos isolados foram encontrados em cada um dos grupos etários, atingindo em alguns casos altos percentuais de positividade; não há uma tendência nítida, ascendente ou descendente, dos percentuais em relação à idade, para nenhum dos microrganismos. Fica evidenciado que, no grupo de crianças em estudo, o potencial de transmissão de agentes disseminados por fezes é muito elevado e ocorre desde a mais tenra idade.

\section{S U M M A R Y}

A sample of 263 children between 0 and 24 months of age, among those attending the Lapa Health Center, São Paulo, Brazil, from October 1963 to September 1964 was studied. Cultures were performed for enteropathogenic Escherichia coli, Shigella, Salmonella, poliovirus, Coxsackie virus and ECHO virus in the feces. The commonest agent isolated was poliovirus $(15.97 \%$ positive) followed by enteropathogenic $E s$ cherichia coli $(10.65 \%)$, Shigella $(9.51 \%)$, Coxsackie $(7.22 \%)$ and finally Salmonella and ECHO $(3.04 \%$ each). Of the 111 subjects that presented positive results, $16,22 \%$ were positive for two or more different agents. The above mentioned microorganisms were present in $42.21 \%$ of the children examined; of the 167 that presented diarrhea the percentage of positives was $47.90 \%$ and of the 96 that had no diarrhea, $32.29 \%$. Association between diarrhea and the presence of an etiological agent was only demonstrated for the Shigella. 
CANDEIAS, J. A. N. et alii - Pesquisa de enterobacteriáceas e enterovírus em crianças normais e com quadros diarréicos agudos. Rev. Saúde públ., São Paulo, 2(2):194-206, dez. 1968.

Results were only suggestive for such association regarding $E$. coli 0111 , Salmonella and Coxsackie A virus. Regarding the other agents there was no evidence of association.

\section{REFERENCTAS BIBLIOGRAFICAS}

1. CANDEIAS, J. A. N. \& CHRISTOVAO, D. de A. - Serodiferenciação de amostras de virus de poliomielite isoladas de crianças vacinadas e não vacinadas com vacina Sabin. (Em vias de publicação.)

2. CaRvalho, R. P. de S. - Contribuicão para o estudo dos enterovirus. Folia clin. biol., 35(1):1-47, Jan. 1966.

3. CosTA, G. A.; COSTA, A. \& BOLANOS, R. - A Escherichia coli na etiologla da diarréia aguda da criança. Bol. Inst. Pueric., Rio de Janetro, 16(1):6-19, Mar. 1959.

4. COSTA, G. A.; COSTA, A. \& BROOKING, C. - As shigeloses e salmoneloses na etiologia das diarréias agudas da crianca. Bol. Inst. Pueric., Rio de Janeiro, 14(2):79-98, Jun. 1957.

5. FERRARI, E. - Diarréias infecciosas da Infancla. Rev. Goiana Med., 10(3-4):141-156, Jul.-Dez. 1964.

6. FISCHER, A. R. - Etiologia bacteriana das diarréias infantis. I. Achados bacteriológicos em lactentes e crianças maiores até 5 anos. J. Pediát., Rio de Janeiro, 26(5):192-201, Mal. 1961.

7. FOURNELLE, H. J.; GRACIAN, M. \& MEDINA, P. - Enfermedades diarreicas en Colombia: informe de una encuesta bacteriológica. Bol. Ofic, sanit. panamer., 61(5) :408-413, Nov. 1966.

8. GAMBLE, D. R. - Isolation of Coxsackie viruses from normal children aged 0-5 years. Brit. med. J., 1(5270):16-18, Jan. 1962.

9. GAMBLE, D. R. et alii - The routine typing of Coxsackle viruses by complement fixation. Mtl. Bull. Minist. Hith Lab. Serv., 22:6-14, Jun. 1963.

10. HAMBLING, M. H.; DAVIES, P. M. \& MACRAE, A. D. - The typing of enteroviruses in tissue culture by neutralization with composite antiserum pools. J. Hyg., Cambridge, 61(4):479-484, Dec. 1963.
11. HORMAECHE, E. et alii - Causes of infantile summer diarrhea. Amer. $J$. Dis. Child., 66(5):539-551, Nov. 1943.

12. KIBRICK, S. - Current status of Coxsackle and ECHO viruses in human disease. Progr. med. Virol., 6:27-70, 1964.

13. LOBO, G. G. B. - Isolamento de poliovírus de fezes de criancas durante um surto de poliomielite ocorrido na cidade de Belém, no período de outubro de 1961 a março de 1962. Rev. Serv. Saúde públ., Rto de Janeiro, 12(1):71-79, Jan. 1962.

14. MAROJA, R. C.; FREITAS, E. N. de \& FERRO, T. L. - Frequiencia de enterobactérias e enteroparasitas em casos de diarréla aguda em menores de 1 ano, Palmares, Pernambuco, 1956. Rev. Serv. Saúde puibl., Rio de Janelro, 10(2):747-757, Dez. 1959.

15. MAROJA, R. C. \& LOWEREY, W. D. Estudos sôbre diarrélas agudas. Ir. Frequiencia de Shigelas e Salmonelas nos casos de diarréla aguda em Santarém, Pará. Rev. Serv. Saúde públ., Rlo de Janeiro, 8(2):585-589, Dez. 1956.

16. MAROJA, R. C. et alii - Estudos bacteriológicos de uma epidemia de diarréia infantll em Fortaleza, Ceará, 1957. $J$. Pediat., Rio de Janeiro, 23(9):377-382, Set. 1958.

17. MORAES, N. L. A. - Epidemiologia das diarréias infantis. Bol. Inst. Pueric., Rio de Janeiro, 17(3):200-204, Set. 1960.

18. MURAhovsCHI, J. et alli - Estudo sóbre a etiologia das diarréias agudas do lactente e ensaio de tratamento com o sulfato de tramicetina e o sulfato de canamicina. J. Pediat., Rio de Janeiro, 28(1):1-50, Jan. 1963.

19. OCAMPO, A. R. - Enteroviral studies in the Phllippines. J. Philipp. med. As8., 43(4) :284-288, Apr. 1967.

20. PARROTT, R. H. - The clinical importance of group A Coxsackie viruses. Ann. N. Y. Acad. Sci., 67 (8):230-240, Apr. 1967.

21. PELUFFO, C. A. et alli - Estudos sobre as salmoneloses em såo Paulo. I. Incldencia dos diferentes tipos de diarreias infantis. Mem. Inst. Butantan, 19:211$-215,1946$. 
CANDEIAS, J. A. N. et alii - Pesquisa de enterobacteriáceas e enterovírus em criancas normais e com quadros diarréicos agudos. Rev. Saúde públ., São Paulo, 2(2):194-206, dez. 1968.

22. RAMOS-ALVAREZ, M. - Cytopathogenic enteric viruses associated with undifferentiated diarrheal syndromes in early childhood. Ann. N. Y. Acad. Sci., 67 (8) :326-331, Apr. 1957.

23. RAMOS-ALVADEZ, M. \& SABIN, A. B. - Characteristics of poliomyelitis and other enteric virus recovered in tissue culture from healthy american children. Proc. Soc. exp. Biol., New York, 87(3): 655-661, Dec. 1954.

24. —_ - Enteropathogenic viruses and bacteria. Role in summer diarrheal diseases of infancy and early childhood. J. A. M. A., 167(2):147-156, May, 1958.

25. - Intestinal viral flora of healthy children demonstrable by monkey kidney tissue culture. Amer. $J$. publ. Hlth, 46(3):295-299, Mar. 1956.

26. ROUQUAYROL, M. Z. - Diarréias infantis em Fortaleza: contribuicão ao seu estudo, com especial referência às shigeloses. Ceará, 1962. (Tese para Docência-Livre - Fac. Farm. Odont. Univ. Ceará).

27. SCHATZMAYR, H. G. \& SALES, H. C. - Investigações sôbre infecçōes por enterovírus no Distrito Federal. Mem. Inst. Osw. Cruz, 64:125-130, 1966.
28. SOMMERVILLE, R. G. - Enteroviruses and diarrhoea in young persons. Lancet, 2(7061):1347-1349, Dec. 1958.

29. TAUNAY, A. E. - Diagnóstico bacteriológico das salmonelas de origem animal, sua importancia e freqüência no Municipio de São Paulo. São Paulo, 1967. (Tese de Doutoramento - Fac. Odont. São José dos Campos.)

30. —_ et alii — Estudo bacteriológico da diarréia do recém-nascido. Hospital, Rio de Janeiro, 49(5):625-634, Mai. 1956.

31. — et alii - Investigações laboratoriais sôbre a enterite infantil por E. coli G.E.I. Rev. Inst. A. Lutz., S. Paulo, 18(n॰ único):45-81, 1958.

32. TRAVASSOS, 'J, et alii - Ocorrência de virus Coxsackie no Rio de Janeiro. II. Isolamento do virus em criancas com distúrbios gastro-intestinais. An. Microbiol., Rio de Janeiro, 2:83-88, 1952/1953.

33. YOUNG, V. M. et alii - Studies of infectious agents in infant diarrhea. III. Bacterial, viral and parasitic agents in feces of Puerto Rican children. Amer. J. trop. Med. Hyg., 11(3):380-388, May 1962. 